\title{
http://doi.org/10.15359/ree.2004-7.8 \\ ¿PUEDE ATRIBUÍRSELE VALOR ESTÉTICO A LA MÚSICA POPULAR? UNA POSTURA FRENTE A ADORNO
}

\author{
Deborah Singer*
}

El presente trabajo se findamenta en las teorías del músico y crítico alemán Theodor W. Adorno (1903 - 1969), quien le atribuyó a la música un papel clave como formadora (o deformadora) de la conciencia humana. Desde su perspectiva, la "buena música" ejerce un rol redentor del individuo (la músicaclásica, por ejemplo), mientras que la "mala música" tiende a mantener el orden existente y enajena al ser humano al privarlo de su capacidad crítica; en esta última categoría ubica al Jazz, el pop y otros géneros musicales a los que no les atribuye ningún valor estético. La autora analiza la postura de Adorno y hace una defensa de la llamada música popular. Para lograrlo, analiza la estética de la música de los pueblos, el folklore y el origen e impacto de ritmos modernos, como es el caso del rap.
This essay is based on the theories of the German musician and critic Theodor W. Adomo (1903 - 1969), who assigned to music a key role as a forming (or deforming) agent of human conscience. From his point of view, "good music" (classical music, for instance) redeems the individual, while "bad music" tends to preserve the existing order and alienates humans, depriving them from their critical capacity; jazz, pop music and other music genres fall into this last category and they are not assigned any aesthetic value. The author analyzes Adorno's position and pleads in favor of popular music. In order to achieve this, she analyzes the aesthetics of music in small towns, folklore, and the origin and impact of modern rhythms such as rap music.

* Pianista chilena. Se graduó en la Universidad Católica de Chile y realizó estudios de posgrado en la Academia Superior de Música de Friburgo, Alemania. Ha realizado recitales en Costa Rica, Chile, Alemania, Rusia, Israel y Estados Unidos. Actualmente se desempeña como docente de la Universidad Nacional y la Universidad de Costa Rica. 


\section{Introducción}

Vivimos en una era de producción masiva. Atrás quedaron las sociedades aisladas del mercado. Hoy las empresas pierden su arraigo nacional y son absorbidas por corporaciones multi-nacionales que se reparten regiones de mercado tan grandes como continentes enteros. A golpe de tambor, la pulpería es desplazada por el supermercado. Los habitantes del planeta, por efecto de la llamada globalización, están expuestos a las mismas manifestaciones culturales y los mismos programas de televisión. El mundo bipolar de la guerra fría dio paso en 1989 a una realidad geopolítica de un solo polo. Todo lo anterior ha contribuido a exacerbar las tendencias deshumanizadoras identificadas por Adomo desde mediados del siglo XX. El individuo ha sido avasallado por la sociedad industrial.

La sociedad capitalista centra su interés en la generación constante de nuevas necesidades, a fin de que el consumidor dé rienda suelta a su libertad de consumir. Libertad supeditada al poder adquisitivo de cada quien. El fin último es el lucro y las relaciones interpersonales resultan afectadas. Consecuentemente, el código moral de la sociedad valora a sus miembros en función de lo que poseen o pueden llegar a poseer y, en menor medida, por lo que son. Este fenómeno se refleja en todos los campos del quehacer humano, pero tiene especial relevancia en el ámbito de la cultura, por estar esta relacionada con la creatividad del ser humano, un rasgo especialmente sensible.

Este trabajo está basado en las teorías del músico y crítico alemán Theodor W. Adorno (1903-1969), quien vivió en carne propia la persecución del régimen nazi, lo que lo forzó a emigrar a los Estados Unidos. El contacto con dos realidades diametralmente opuestas, por un lado la dictadura nazi y, por otro, la tierra prometida de "la libertad y las oportunidades", lo llevó a elaborar diversos ensayos en los que cuestiona el rol del individuo en la sociedad. La posición de Adorno es negativa y pesimista, porque considera que la sociedad industrial da origen a seres humanos uniformes, totalmente alienados, sin que haya una forma concreta de evitarlo. Sin embargo, le atribuye a la música un papel clave como formadora (o deformadora) de la conciencia humana. Según él, la "buena música" ejerce un rol redentor porque confronta al individuo con el mundo que lo rodea, transformándolo en una mejor persona. En contraposición Adorno critica la llamada "mala música", que tiende a mantener el orden existente y más bien enajena al individuo al privarlo de su capacidad crítica y de su conciencia como ente único. En la categoría de la "mala música", Adorno ubica al jazz y a la ahora llamada música pop, géneros musicales a los cuales no les atribuye ningún valor estético y los considera propagadores del orden existente. 
En el ámbito de las manifestaciones artísticas, la posición de Adorno aún treinta años después de su muerte, sigue suscitando debates. El fenómeno de la masificación de la cultura, y la pérdida del individualismo siguen siendo temas de nuestro tiempo. Históricamente, la posición de Adorno responde a una situación que se agudizó con la expansión del capitalismo: la profundización de la brecha entre la llamada música "seria" (música clásica), y la música producida para el consumo de la gente común (música popular). En este ensayo exploraré el valor estético que esta última posee, considerando su forma y origen y los niveles en que afecta a los seres humanos.

\section{El punto de vista de Adorno}

\section{La industria cultural}

Adorno elabora su pensamiento en el período del siglo XX, cuando la humanidad es afectada por la traumática experiencia de las guerras mundiales, y el ascenso de los regímenes totalitarios. Con este trasfondo, no sorprende su visión negativa y desesperanzada de la realidad. Su obra está influenciada por la doctrina marxista, en la que la música (al igual que toda manifestación artística) es un fenómeno ideológico enmarcado por la historia de los modos de producción y la lucha de clases. Lo que llamamos obras musicales -la organización de sonidos en el tiempo- es una entidad histórico-social, un producto más del hombre y su historia.

Adorno observa cómo el individuo es atacado simultáneamente por los colectivismos nazi y comunista, por la seudo-democracia del capitalismo, y por una ciencia y tecnología negadoras de la identidad de cada persona. En su obra "La Industria cultural", denuncia cómo la sociedad industrial y capitalista ha sofocado la autonomía y la libre creatividad. La industria cultural, controlada por los grandes consorcios capitalistas, esquematiza y cataloga la cultura para llevarla al plano de la administración. Con el apoyo de la propaganda y de los medios de comunicación masiva (radio, cine, televisión, prensa escrita, etc.), se produce una estandarización progresiva, y el arte es degradado a la categoría de producto de intercambio. Se fomenta la producción en masa, de modo que el individuo acepta consumir lo que se le ofrece sin oponer resistencia alguna. Las autoridades ejecutivas no producen nada que vaya en contra de sus intereses, y la prueba está en que los productos que salen al mercado son todos de una extraordinaria similitud; a lo sumo crean la ilusión de que hay diferencia para que el individuo sienta que es libre de escoger.

En la sociedad actual, la actividad intelectual se expone a ser dominada por las relaciones económico-sociales. En el campo de las artes, el desarrollo de 
la cultura industrial ha conducido al predominio del "efecto" y el detalle técnico, sobre la obra en sí misma. Ejemplo de ello es la producción cinematográfica, que constituye la convergencia de todas las formas artísticas (plástica, drama, música, etc.) degradadas para ser más accesibles al público medio, y presentadas con gran vistosidad para transformar la película en un espectáculo atractivo. El material se entrega procesado y "a medio digerir" para no dar lugar a la imaginación o a la reflexión crítica. La gente reacciona automáticamente a estos estímulos, porque ha sido moldeada de acuerdo a un patrón común.

Adorno enfatiza el tema del entretenimiento. La industria cultural es el negocio del entretenimiento. Este le ofrece al individuo una vía de escape de su realidad cotidiana, de sus problemas y frustraciones. Pero se trata de un escapismo ficticio, porque es efímero y no implica esfuerzo mental alguno. Para Adorno, la risa no manifiesta felicidad, sino más bien la hiere; constituye la liberación de todo escrúpulo con lo cual da paso a la barbarie. Con ello, la cultura de la distracción da origen a la cultura de la barbarie, la depravación de la cultura.

La cultura de las masas rechaza toda innovación porque representaría un riesgo, un desafío al orden establecido. Todo lo que se repite es deseable, y cuanto más uniforme, mejor. La masificación fluye hacia una deshumanización tecnológica donde se le da al hombre demasiado, haciéndole la vida segura, pero lo que él recibe verdaderamente es muy poco, y de mala calidad. El individuo incluso termina por utilizar su propio disgusto como impulso para abandonarse al poder del que está harto; y la felicidad solo puede alcanzarla en la medida en que se entregue al sistema y acepte la dominación sin protestar.

\section{Análisis crítico de "La industria cultural"}

La sociedad industrial que ha producido la cultura occidental, ciertamente no constituye un modelo perfecto de organización, pero tiene el mérito de fomentar el principio de la libertad. Independientemente de la forma en que este concepto sea encausado, lo cierto es que un sistema que admite la posibilidad de que haya disidencia, es flexible y susceptible de ser mejorado. La sociedad industrial defiende valores que históricamente han abierto vías al desarrollo personal, al progreso de la ciencia y del arte. Muchos cambios han ocurrido desde el trabajo infantil en las minas de carbón inglesas. El desarrollo industrial ha ido creciendo aparejado con una organización social que cree en la apertura y el esfuerzo individual como vía legítima para alcanzar el progreso personal. Esta ruta de evolución de los acontecimientos no pudo ser prevista por Adorno, quien estaba reflexionando al calor de los cambios de la revolución industrial y las guerras. 
Arte popular es simplemente arte de los pueblos, y detrás de cada obra popular hay información sociológica, política, histórica, lingüística, que nos documenta acerca de la vida de la gente, su escala de valores, sus creencias y aspiraciones. Los antecedentes de cada manifestación del arte popular recrean y recuerdan a quienes lo disfrutan las bases mismas de su identidad.
Adorno (al igual que Ortega y Gasset y otros) se refiere a un mega grupo humano como la "masa". El término sugiere una muchedumbre informe y dócil, ya sea para realizar una revolución social o para perpetuar el orden existente. Pero los autores parecen olvidar que las supuestas "masas" están compuestas por individuos, cada uno con su propia historia, deseos, ansiedades, esperanzas, recuerdos, y su propia problemática. ¿No somos todos parte de la masa? ¿Cuál es el factor que determina que unos pocos "elegidos" se liberen de ella? De ser el grado de educación, se estaría privilegiando a la élite que tiene acceso a ella. Pero cabe destacar que no todos los que llegan al pináculo del sistema educativo tienen el nivel de conciencia y postura crítica frente al mundo que podría esperarse de su condición. Hasta el mismo Ortega y Gasset habla del tecnócrata que, como consecuencia de una progresiva sobre-especialización, adolece de una visión fragmentada de la realidad. Es él, consecuentemente, un tipo de "Fachidiot", quien sabe mucho de muy poco, y demasiado poco de lo fundamental, es decir, de su papel en el entorno social. A esta perniciosa tendencia se han contrapuesto los curricula de muchas universidades mediante la inserción de estudios generales y la formación humanística.

Por otra parte, Adorno juzga negativamente el rol que cumplen los medios de comunicación social. Si bien es cierto que estos pueden ser manipulados por interese mezquinos, cabe destacar que en las sociedades más democráticas los medios de comunicación representan la conciencia social, en la medida en que denuncian las situaciones de corrupción y constituyen un contra-poder al orden establecido. Existen numerosos ejemplos de participaciones destacadas de la prensa, gracias a las cuales los actores políticos han sido obligados a renunciar, haciendo posible una rectificación. También a través de la prensa se ha logrado mejorar la comunicación entre todos los ciudadanos del mundo. Si el individuo rechaza lo que no comprende, y no comprende lo que no conoce, es de vital importancia contar con medios informativos que le den acceso a la realidad de otro tipo de sociedades, con modos de vida diferentes a los propios. ¿No es esta la mejor confrontación con nuestros propios juicios de valor? Si logramos familiarizarnos con grupos humanos que piensan distinto, ¿No es más fácil encontrar el camino que lleva a la tolerancia y al entendimiento entre los pueblos? 
Adorno hace un análisis de la música contemporánea, en que le atribuye una importancia social de primer orden. En la primera mitad del siglo XX, período aludido por Adorno en su obra, surgieron los movimientos artísticos vanguardistas que rompieron con los cánones establecidos, creando una nueva forma de lenguaje. Siguiendo esta tendencia, hubo un replanteamiento acerca del rol que el arte debe cumplir en la sociedad: discrepancia y confrontación. Según esta postura, el arte no está destinado al goce (con que tradicionalmente se le asocia), no debe deleitar, sino desafiar lo predecible y habitual, los esquemas preconcebidos. En el ensayo "Dissonanze" escribió: "El arte no debe garantizar o reflejar la paz y el orden, sino forzar a aparecer lo que se ha dejado bajo la superficie, y resistirse así a la opresión de la superficie, de la fachada". La música, particularmente, tiene la obligación de exponer las contradicciones de ese mundo espantoso, la alienación en que viven los seres humanos y la fragmentación de la vida moderna que parcializa la visión del mundo de las mayorías.

Según este planteamiento, la música es un fenómeno fundamentalmente social, pues se trata de una construcción cultural creada por el hombre, para ser percibida por los demás, con la función de lograr una confrontación del individuo consigo mismo, que desencadene un cambio en su modo de pensar y lo conduzca a un nivel superior de conciencia y desarrollo personal.

No obstante, Adorno se contradice posteriormente al sostener que la música no debe cumplir función alguna, no debe apoyarse en nada externo a ella, ni debe ser asociada a ninguna otra cosa que no sea ella misma. ¿Cómo puede conciliarse esta posición con la realidad, si también se la involucra en asuntos de poder y de control, y se la considera un medio para lograr el cambio social? Si el sistema impone similitud a cosas naturalmente diferentes, al asumir que el rol de la música es impactar y destruirlas presuposiciones, ¿Cómono atribuirle una función “extra musical”?Adorno resuelve esta paradoja afirmando que hay una permanente tensión entre los contrarios (dialéctica hegeliana), y la verdad no es susceptible de ser definida y reducida a un patrón inteligible. Esta conclusión no me parece satisfactoria.

Por otra parte, tenemos la contradicción entre la música verdaderamente autónoma, y la música para las masas. La primera se resiste al consumo fácil. Representa la rebelión, la protesta, el distanciamiento de lo establecido, el compromiso con la innovación. Para Adorno, el mejor representante de ella es Schoenberg, creador del sistema dodecafónico. En la dodecafonía, el compositor se constriñe voluntariamente entre los límites de una construcción musical, rebelándose contra la tonalidad, contra el lenguaje tradicional, dándole prioridad a la disonancia. Con ello salva la subjetividad del individuo y a la música de 
caer en el rango de un producto mediocre más para el consumo de las masas. El problema es que de esta forma, la música se transforma en el último fetiche: un objeto inalcanzable que por ser tan noble e incomprensible, solo unos pocos tienen acceso a él. Esta música innovadora no alcanza a impactar a la sociedad a la que pretendía despertar de su letargo. Este conflicto queda sin resolverse, y de allí viene la desesperanza a menudo presente en la obra de Adorno.

Por su parte, la música para las masas es un producto de consumo fácil cuya calidad resulta objetable. Adorno se refiere concretamente al jazz, el cual rechaza con fervor catalogándolo de música liviana y primitiva, y le niega cualquier valor social y estético. Es dudoso que él haya estudiado seriamente los orígenes y la producción jazzística de su tiempo, de otro modo su posición no habría sido tan categórica. De hecho, el reconocimiento que se le ha dado al jazz en los últimos cincuenta años es tal, que forma parte del currículum de las principales academias de música del mundo.

\section{¿Tiene valor la música popular?}

En la actualidad, la producción de música popular llega a niveles insospechados, con un consumo masivo a nivel mundial. Resulta difícil aceptar que la humanidad escucha música popular por conformismo, modorra o estupidez. Por muy influenciable que sea el público por parte de la propaganda, es innegable que el consumo de la música y el arte popular en general, responde a una necesidad humana, y más que rechazarlo a priori por no responder a los cánones de valor estético a los que estamos acostumbrados, conviene establecer un marco crítico donde se lo analice bajo sus propias reglas. Especial interés posee el estudio de los orígenes de la música popular que, con frecuencia, nos llevan hasta las raíces mismas de la formación de las sociedades contemporáneas.

\section{¿Qué se entiende por estética?}

El término "Estética" fue acuñado por el filósofo alemán A. G. Baumgarten en 1735, quien lo tomó de la palabra griega "aistheta" (percepción), para designar precisamente la ciencia de la percepción. Posteriormente, el término fue relacionado al concepto de belleza, y de sensibilidad al arte y la belleza, es decir, el buen gusto. Al ser percepción menos que concepción, Kant catalogó la estética como una ciencia menor de cognición, basada en la experiencia puramente sensorial que no deja nada al ejercicio de la reflexión. Conmueve al espíritu en forma pasajera. Pero la experiencia estética, al ser una parte fundamental de la 
identidad de los pueblos, se resiste al cambio propuesto por la moda y, por lo tanto, permanece a través del tiempo.

Todo aquel que es esclavo de sus sentidos logra una forma de liberación cuando tiene una experiencia estética. Esta es la función moral de la estética. Además, la estética cumple una función social, porque la percepción es relativa a la experiencia del grupo social, a su escala de valores y su historia. Cuando hablamos de situaciones estéticas en nuestra vida diaria, esto depende de un modo de relación específico entre nosotros y el objeto (cualquiera que sea), donde respondemos positivamente a la cualidad de experiencia de este, y procesamos la información que obtenemos de él. En el proceso hay un equilibrio entre la participación cognitiva y la participación afectiva, es decir, hay un balance entre el estado intelectual y el estado emocional.

El concepto de estética es afirmativo, en el sentido de que se orienta hacia un sentimiento de perfección, aunque sepamos que nada en el mundo es perfecto. La estética se desarrolló en conexión con el desarrollo del arte serio, por eso muchos se niegan a "rebajarlo" al contexto de la vida diaria. Concluyo que el arte popular y otras manifestaciones culturales no pueden ser catalogadas automáticamente como formas inferiores de arte. La estética no se contrapone necesariamente al arte popular.

\section{El arte popular}

Hay una serie de productos culturales usualmente llamados "arte popular", por ejemplo, las comedias musicales, los dibujos animados, la música rock, las series de televisión, el cine, las novelas de ciencia ficción y los bailes populares, entre muchas otras manifestaciones.

Las últimas generaciones se han formado en contacto con el arte popular, a pesar de que se nos enseñó que es de peor calidad. En este contexto, el cine, la televisión y, más recientemente, Internet, han jugado un papel preponderante. Hay un replanteamiento de los conceptos de "arte" y "estética". La tendencia actual es despreciar cosas triviales basándose en su popularidad como criterio. Si bien no podemos aseverar que cada canción popular es una obra de arte, tampoco podemos afirmarlo de cada obra del repertorio clásico. En el fondo, no se trata de reconciliar dos tradiciones culturales diferentes, sino dos aspectos del hombre en sí mismo. Una misma persona puede disfrutar tanto el arte serio como el popular. No hay una dicotomía insalvable en esa posición.

Arte popular es simplemente el arte de los pueblos, y detrás de cada obra popular hay información sociológica, política y histórica y lingüística, que nos documenta acerca de la vida de la gente, su escala de valores, sus creencias y 
aspiraciones. Los antecedentes de cada manifestación del arte popular recrean y recuerdan a quienes lo disfrutan las bases mismas de su identidad.

Por otra parte, cuando enfrentamos el arte popular en el marco de la vida diaria, es de vital importancia elaborar un marco de análisis crítico, en estrecha conexión con el concepto de estética. Este marco debe ser apropiado al área específica de cada manifestación de arte popular. Debemos perfeccionar nuestro limitado poder de observación, nuestra restringida escala de valores, y nuestro limitado vocabulario crítico, a fin de explorar y maximizar el potencial cualitativo del arte popular en nuestra relación cotidiana con él.

Cuando se menciona un "nivel más alto de experiencia", se alude a lo profundo, eterno o etéreo. En el arte popular, se requiere desarrollar sensibilidad por un nivel más bajo de experiencia, que es eminentemente superficial, efímero y corporal. Ambos niveles están relacionados y se presentan independientemente de la formación, o clase social de la que provenga la persona. De esta forma es perfectamente posible que un intelectual disfrute escuchando a "Los Beatles" de la misma forma en que se deleita escuchando a Brahms.

En el arte popular, lo monótono, rutinario y predecible interactúa dinámicamente con lo inmediato, espontáneo o directo en el proceso de experiencia. Estos últimos componentes del proceso crean un patrón de escape temporal del control y la represión que sufre el hombre el contexto de nuestra civilización, pues asimila lo instintivo, agresivo e irracional, de modo que podamos disfrutarlo sin remordimiento. Lo rutinario, por su parte, nos da la tranquilidad de encontrarnos frente a lo que nos resulta familiar y conocido, pero con un matiz distinto que da la ilusión de algo nuevo. Hay una interacción dinámica entre todos estos elementos. El concepto de estética puede abarcar el arte popular de la misma forma en que abarca el arte serio, especialmente en vista de su importancia, más allá del uso que se haga de él.

$\mathrm{El}$ arte popular existió siempre, pero como concepto (de la forma en que lo entendemos actualmente) nació de los radicales cambios que se produjeron en el siglo XIX con la revolución industrial y el desarrollo de la producción, distribución y consumo masivo de los productos culturales, y se aceleró con su comercialización facilitada por el advenimiento de nuevos y más ubicuos medios de comunicación.

\section{El folklore}

El folklore corresponde a la herencia cultural de un grupo humano con identidad propia, que se transmite de padres a hijos, independientemente de la difusión que hacen los medios de comunicación. Cada localidad del mundo tiene su propia manera de hacer las cosas, y esto se aplica al ámbito de la creación 
artística. Mantener la tradición y conservar este patrimonio le garantiza a cada pueblo su supervivencia e identidad.

En el campo de la música, los pueblos suelen aferrarse a ese patrimonio por medio del "rescate" de viejas melodías que cantan las abuelas. Un ejemplo de ello es el caso de la folklorista chilena Violeta Parra, quien recorrió el país de norte a sur en la década de los cincuentas, y reprodujo por medio de grabaciones los temas que escuchó, o bien, estos le sirvieron de inspiración para crear su propia música. Esta se transformó en un canto de protesta prohibido durante los años de la dictadura militar, de modo que en la actualidad estas canciones son parte de la memoria colectiva de toda una generación de chilenos. En contraposición a la tesis de Adorno, en este caso, una manifestación del arte popular hace al hombre más libre al permitirle recrear los antecedentes de su cultura.

Otro caso interesante es el del "merengue" en la República Dominicana. Originalmente nació como la expresión musical espontánea de los esclavos negros que añoraban la tierra de la cual habían sido violentamente apartados. En sus muy escasos períodos de descanso, estos esclavos reconstruyeron sus instrumentos tradicionales y tocaron la música aprendida de sus ancestros. Con el transcurso del tiempo, el merengue superó la barrera racial, dejó de ser rechazado por la población blanca, y se transformó en una forma musical que es parte de la identidad de la República Dominicana y varias naciones del Caribe. Este es un ejemplo concreto de la evolución de un arte popular originalmente desdeñado por la clase dominante que se transformó en una manifestación cultural de toda la sociedad que sucedió a la colonia.

\section{La discusión en torno a la música}

Desde épocas remotas, filósofos, científicos y músicos han meditado en torno a la música. La fascinación que ejerce se debe sobre todo a la complejidad de los medios técnicos y del lenguaje de que se sirve: se expresa sin que se pueda aprehender su objeto. El complejo lenguaje de la música no dice nada acerca de nada, sin embargo, todos le reconocen un poder expresivo aunque nadie puede precisar de qué se trata.

Al ser el fenómeno musical tan complejo, los autores se centran en el sonido como elemento físico-matemático, reflexionan en torno a la función técnicolinguística de la música, a su función social y artística. Cualquiera de estos aspectos puede ser estudiado en forma preferencial por un determinado autor, en un período específico de la historia. Esto genera las diferentes corrientes estéticas, a menudo contrastantes, que enfrenta el quehacer musical. 
En la antigua Grecia, Platón y Aristóteles consideraban la música como un poderoso medio para conseguir fines concretos en el contexto social y político. Durante la Edad Media la música se transformó en un medio para expresar la religiosidad de los individuos, pero es sólo en los siglos XVII y XVIII cuando se precisan y se concretan los intereses de los filósofos, de los teóricos y del público en general, por los temas musicales. De hecho, el concepto de "arte" (en el moderno sentido de la palabra) comenzó a tomar forma al ser categorizados ciertos productos culturales (pintura, música escultura, poesía, arquitectura) dentro de un solo concepto.

El gran problema de la estética del iluminismo es la relación entre música y poesía. Para el espíritu racionalista-cartesiano de aquel tiempo, el arte y el sentimiento no disfrutan de autonomía propia y no cumplen ninguna función esencial en la vida del hombre; representan solo formas inferiores de conocimiento. En las clasificaciones jerárquicas de arte, la música a menudo se encuentra en último lugar, y la poesía en el primero. La razón es muy simple: la música se dirige a los sentidos, al oído; la poesía en cambio, se dirige a la razón. Este hecho le da la supremacía.

En contraposición a lo anterior, Rameau sostiene que la música nos gusta y experimentamos placer al escucharla, precisamente porque expresa (a través de su armonía) el divino orden universal, la misma naturaleza. Por su parte, Rousseau revaloriza el sentimiento y la considera como el lenguaje que más de cerca habla al corazón humano.

Durante el romanticismo, por ser la música un arte asemántico (no puede decir nada de lo que se puede comunicar con el lenguaje común), se sitúa infinitamente por encima de cualquier orro medio de comunicación. Cuanto más alejada está de cualquier tipo de conceptualidad, con mayor profundidad capta la realidad.

A fines del siglo XIX comienza a desarrollarse un nuevo enfoque estético que da prioridad a la forma por sobre el sentimiento. La música es forma pura, y en cuanto a belleza, no tiene ningún fin (Hanslick). Lo interesante de esta pequeña revisión es constatar que la obra musical no puede ser separada del contexto histórico y social del que surge. Para comprenderla es necesario situarla en el cuadro de la vida real en que nació. Cada época favoreció el predominio de un juicio de valor determinado, que podía contrastar radicalmente con el precedente. De hecho, cuando aparecieron los primeros estudios sobre la música antigua y la música oriental, se empezó a desmitificar la tradición occidental y el sistema tonal comenzó a tambalearse, pues demostró no ser ni único ni eterno. ¿Cómo emitir un juicio de valor en tomo al resultado sonoro de un gamelan de las islas de Java y Bali? ¿Qué estructura formal se le puede atribuir a los tambores africanos? 


\section{La autonomía}

Adorno le da a la autonomía un papel preponderante, en la medida en que es la única forma de resistirse a la uniformidad impuesta por la industria de masas. Lo que me parece discutible es atribuirle autonomía a cualquier obra artística. Estas son producto de la creación de personas, que viven en un momento determinado de la historia, y bajo condiciones socioculturales específicas. De esta forma, resulta utópico pretender que la obra se abstraiga del medio, para independizarse totalmente de cualquier referencia externa. De hecho, es el individuo el que le atribuye (o no) un valor estético, dependiendo de su propia percepción. Incluso aquellos que defienden la importancia de la forma por sobre el contenido, en una obra que teóricamente debería carecer de todo significado, están respondiendo a una determinada tendencia estética que nace en un contexto histórico específico.

Sí me parece relevante el tema de la autonomía del individuo. Es importante desarrollar un grado de conciencia que permita cuestionar en forma crítica, y tenga la sensibilidad de reconocer lo particular dentro de un todo aparentemente uniforme. La naturaleza humana es diversa y compleja. Conviene impartir un tipo de educación que favorezca la libertad, que analice la vida con profundidad crítica, y problematice la realidad, para transformarla en un proyecto más humano. Solo en la medida en que se reconozca a cada individuo dentro de la "masa" como una entidad única e invaluable, será posible iniciar el largo camino que lleva al descubrimiento de la propia identidad y a la verdadera autonomía. Solamente renunciando a las etiquetas y a las generalizaciones arbitrarias, se rescatará la integridad de lo diferente.

El arte es un aspecto más de este todo orgánico. La educación mușical debería tender a fortalecer la habilidad de las personas de escuchar y crear música, independientemente del tipo de música de que se trate. En el caso de la música popular, convendría analizar atentamente el trasfondo de la obra, de modo de favorecer una actitud crítica, ojalá, no de rechazo. La meta es llegar a una educación multicultural a través de la música, es decir, educar musicalmente.

\section{Conclusiones}

La música es una manifestación del quehacer humano. Lo que un grupo social escucha está más relacionado con sus hábitos y modo de vida, que con las características formales y estructurales de la obra musical propiamente. El hecho de que una obra sea extremadamente popular tiene que ver con la manera en 
que el público se identifica con ella; de alguna forma está llenando un vacío o expresa un cierto grado de frustración, que está estrechamente ligado al contexto histórico en que nace. La música más escuchada durante los años de la década de los sesentas tenía que ver, sobre todo, con el movimiento hippie, que se rebela contra los convencionalismos y la guerra pero, lo hace de una forma eminentemente pacífica.

Distinto es el caso del rap en la actualidad, pues nace de la rabia y frustración del pueblo negro, con una alta dosis de agresividad que se traduce en un texto a menudo insolente, un ritmo estático de principio a fin, y una línea melódica totalmente ausente. Es decir, prescinde de cualquier elemento que pueda "ablandar" su discurso dándole algún grado de emotividad. Para el escucha no habituado, el rap puede resultar chocante, provocando un rechazo inmediato. Pero, ¿No es a esto a lo que se refería Adorno al hablar de una música cuyo fin es confrontar al individuo consigo mismo?

El estudio de la música popular nos ayuda a comprender el comportamiento de la sociedad, pues expresa las motivaciones y sentimientos prevalecientes. Un sociólogo atento a la música popular podría descifrar el mensaje subyacente y contribuir con recomendaciones útiles para corregir aquello que no está dando resultado.

Al catalogar Adorno a toda la música de entretenimiento como "lo mismo", se niega a explorar una importante fuente de conocimiento, aislándose por exclusión de un grupo humano significativo. Me parece que limando las asperezas entre los distintos modos de hacer música, es más probable llegar a cada individuo y mostrarle el enorme mundo que está a su alcance. Si un profesor de música muestra interés por el material musical que escuchan sus alumnos, logrará a su vez que estos no rechacen a priori otras formas de hacer música (a ellos también puede resultarles aburrida la obra de Bach porque suena siempre igual, "lo mismo" de principio a fin).

El mundo es más grande de lo que pensamos. La cultura occidental prevaleció sobre muchas pequeñas civilizaciones, imponiendo un criterio único y estandarizado acerca de cómo deben hacerse las cosas. Esto no significa necesariamente que todo lo demás haya desaparecido. Más bien, es nuestra responsabilidad redescubrir esa diversidad y difundirla. De este modo favorecemos la tolerancia, en la medida en que cada uno toma conciencia de que existen cosmovisiones diferentes a la suya, igualmente válidas y valiosas.

En este aspecto, los medios de comunicación cumplen un rol preponderante en la medida en que permiten a la humanidad tener acceso a la producción artística de diversas culturas. De ser así, la visión negativa que Adorno tiene de ellos queda superada por la contribución que pueden hacer a favor de un mayor entendimiento entre los pueblos. 
La importancia del fortalecimiento de las identidades nacionales en el contexto de la globalización ha aumentado. No pareciera conveniente que los pueblos pierdan sus raíces al integrarse a la cultura mundial. Lo que tiene sentido es lograr la integración a pesar de las diferencias y compartir las raíces culturales de cada pueblo para enriquecer a la comunidad del planeta.

\section{Referencias}

Adorno T. (2000). Sobre la música. Ediciones Piados. I.C.E. de la Universidad Autónoma de Barcelona.

Bowman W. (1998). Music as Social and Political Force. Philosophical Perspectives on Music (304-52). Oxford University Press.

Camacho D. (1972). La dominación cultural en el subdesarrollo. Editorial Costa Rica, San José Costa Rica.

Fubini E. (1970). La estética musical del siglo XVIII a nuestros días. Barral Editores, S.A. Barcelona.

Horkheimer M., T. Adorno. La industria cultural. Iluminismo como mistificación de masas. Monte Ávila Editores C. A.

Park S. B. (1993). An aesthetics of the Popular Arts. Almqvist \& Wiksell International, Uppsala.

Rader M. A Modern Book of Esthetics. An Anthology. Holt, Rinehart and Winston, University of Washington. 